\title{
Highly Sensitive and Selective Gas Sensors Using Catalyst-Loaded $\mathrm{SnO}_{2}$ Nanowires
}

\author{
In-Sung Hwang and Jong-Heun Lee ${ }^{+}$
}

\begin{abstract}
Ag- and Pd-loaded $\mathrm{SnO}_{2}$ nanowire network sensors were prepared by the growth of $\mathrm{SnO}_{2}$ nanowires via thermal evaporation, the coating of slurry containing $\mathrm{SnO}_{2}$ nanowires, and dropping of a droplet containing $\mathrm{Ag}$ or Pd nanoparticles, and subsequent heat treatment. All the pristine, $\mathrm{Pd}$-loaded and $\mathrm{Ag}$-loaded $\mathrm{SnO}_{2}$ nanowire networks showed the selective detection of $\mathrm{C}_{2} \mathrm{H}_{5} \mathrm{OH}$ with low cross-responses to $\mathrm{CO}, \mathrm{H}_{2}, \mathrm{C}_{3} \mathrm{H}_{8}$, and $\mathrm{NH}_{3}$. However, the relative gas responses and gas selectivity depended closely on the catalyst loading. The loading of Pd enhanced the responses $\left(R_{a} / R_{g}: R_{a}\right.$ : resistance in air, $R_{g}$ : resistance in gas) to $\mathrm{CO}$ and $\mathrm{H}_{2}$ significantly, while it slightly deteriorated the response to $\mathrm{C}_{2} \mathrm{H}_{5} \mathrm{OH}$. In contrast, a 3.1-fold enhancement was observed in the response to $100 \mathrm{ppm}_{2} \mathrm{H}_{5} \mathrm{OH}$ by loading of $\mathrm{Ag}$ onto $\mathrm{SnO}_{2}$ nanowire networks. The role of $\mathrm{Ag}$ catalysts in the highly sensitive and selective detection of $\mathrm{C}_{2} \mathrm{H}_{5} \mathrm{OH}$ is discussed.
\end{abstract}

Keywords : Gas Sensor, $\mathrm{SnO}_{2}$ Nanowires, Catalyst, Selective Detection

\section{INTRODUCTION}

Crystalline oxide nanowires(NWs) are promising gas sensor materials on account of their high surface area-tovolume ratio, less agglomerated configuration and good crystallinity[1,2]. When the diameters of n-type oxide semiconductor NWs are comparable or smaller than two times the Debye length, NW gas sensors become highly sensitive due to effective electron depletion[3]. Although a single NW can be fabricated as a gas sensor using sophisticated electrode patterning technology such as ebeam lithography[4], the high cost for processing restricts its potential applications. In comparison, a networked configuration of NWs can be fabricated simply through routes such as slurry coating[5] and direct growth of NWs on catalytic layers[6]. Thus, NW networks are more practical nanoarchietectures for gas sensor applications.

High gas response, fast response speed and high selectivity are three important gas sensing characteristics. It has been known that the chemoresistive contacts between NWs enhance the gas response[5]. From this point of view, NW network sensors have an advantage over single NW sensor. Moreover, in oxide NW networks, the rapid and effective diffusion of the analyte gas over the entire sensor surface via the less agglomerated NW networks facilitates

Department of Materials Science and Engineering, Korea University ${ }^{+}$Corresponding author: jongheun@korea.ac.kr (Received: Feb. 3, 2012, Accepted : Feb. 15, 2012) a high gas response and fast response speed[7]. The gas response and selectivity of oxide NW sensors can be enhanced further by loading noble metal or metal oxide catalysts to promote the gas sensing reaction[8-10]. Note that the less agglomerated network configuration is advantageous for loading catalysts uniformly.

In this work, two different catalysts( $\mathrm{Ag}$ and $\mathrm{Pd}$ ) are loaded onto $\mathrm{SnO}_{2} \mathrm{NW}$ network sensors using a solution coating and their gas sensing characteristics are investigated. The main focus of this work is directed at the design of highly sensitive and selective gas sensors and to the understanding of the role of noble metal catalysts in the gas sensing reaction.

\section{EXPERIMENTAL}

\subsection{Preparation of $\mathrm{SnO}_{2} \mathrm{NWs}$}

The $\mathrm{SnO}_{2} \mathrm{NWs}$ were synthesized by thermal evaporation using Sn metal powder(99.999 \%). An Au (30 A)-coated Si substrate was placed downstream of the source material in a quartz tube(inner diameter: $28 \mathrm{~mm}$, length: $800 \mathrm{~mm}$ ). The pressure of the processing tube was maintained at about $10^{-2}$ Torr by mechanical pumping to ensure a low gas pressure. NWs were grown at $750{ }^{\circ} \mathrm{C}$ for 20 min with an $\mathrm{O}_{2}$ flow rate of $0.5 \mathrm{sccm}$. 


\subsection{Sensor fabrication and the loading of $\mathrm{Ag}$ or Pd}

The $\mathrm{SnO}_{2}$ NWs were separated from the Si substrate by the immersion of the as-synthesized substrate in isopropylalcohol solvent and a subsequent ultrasonic treatment. After removing the solvent and drying, the $\mathrm{SnO}_{2}$ NWs were mixed with ethyl celluose and $\alpha$-terpineol and coated on alumina substrates with two Au electrodes(on the top) and micro-heaters(on the bottom)(Fig. 1a). The sensor was heat-treated at a heater power of $500 \mathrm{~mW}$ for $2 \mathrm{~h}$ in order to remove all organic content. Ag and $\mathrm{Pd}$ nanoparticles with an average size of $\sim 15 \mathrm{~nm}$ were prepared according to the procedure described by Murphy et al[11]. The Ag or Pd catalysts were loaded onto the sensor element by dropping a slurry droplet $(10 \mu l)$ containing $\mathrm{Ag}$ or $\mathrm{Pd}$ nanoparticles and subsequent heat treated at the heater power of $500 \mathrm{~mW}$ for $2 \mathrm{~h}$.
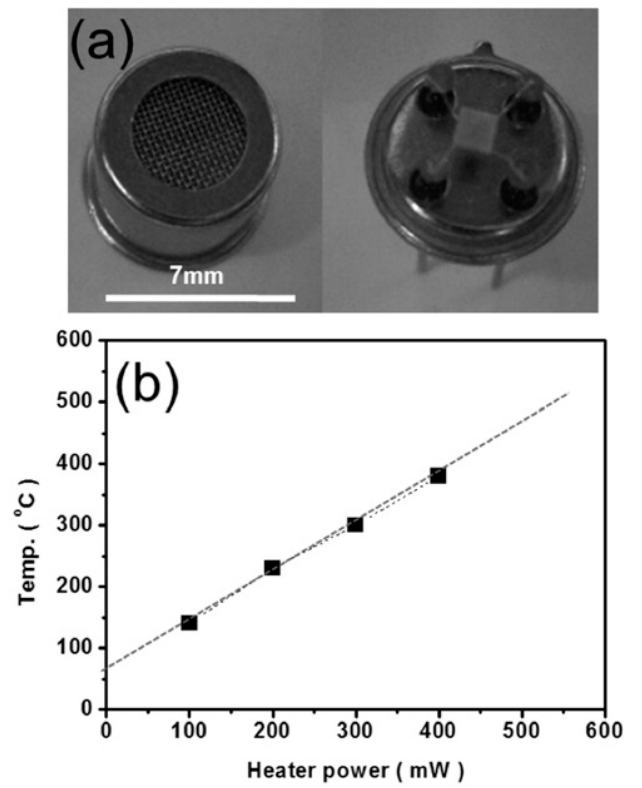

Fig. 1. (a) Sensor structure and (b) sensor temperature as a function of heater power.

\subsection{Gas sensing characteristics}

The sensor temperatures were controlled using the microheater underneath the substrate and were measured using an IR temperature sensor(Rayomatic 14814-2, Euroton IR tec Co.). Heater powers of $100 \mathrm{~mW}, 200 \mathrm{~mW}$, $300 \mathrm{~mW}$ and $400 \mathrm{~mW}$ heated the substrates to $140{ }^{\circ} \mathrm{C}$, $230{ }^{\circ} \mathrm{C}, 300{ }^{\circ} \mathrm{C}$, and $380{ }^{\circ} \mathrm{C}$, respectively (Fig. 1b). The gas responses $\left(S=R_{a} / R_{g}, R_{a}\right.$ : resistance in air, $R_{g}$ : resistance in gas) to $200 \mathrm{ppm} \mathrm{CO}, \mathrm{H}_{2}, \mathrm{C}_{3} \mathrm{H}_{8}, \mathrm{NH}_{3}$, and $\mathrm{C}_{2} \mathrm{H}_{5} \mathrm{OH}$ were measured. Gas concentrations were controlled by changing the mixing ratio of the parent gases(100 ppm $\mathrm{CO}, \mathrm{H}_{2}$, $\mathrm{C}_{3} \mathrm{H}_{8}, \mathrm{NH}_{3}$, and $\mathrm{C}_{2} \mathrm{H}_{5} \mathrm{OH}$, all in an air balance) and dry synthetic air. The DC-2 probe resistances were measured using an electrometer interfaced with a computer.

\section{RESULTS AND DISCUSSIONS}

\subsection{Characterization of sensing materials}

The $\mathrm{SnO}_{2} \mathrm{NWs}$ grown by thermal evaporation were several tens of micrometer long and $80 \mathrm{~nm} \sim 150 \mathrm{~nm}$ thick (Fig. 2a). From the high resolution lattice image and selected area electron diffraction, each $\mathrm{SnO}_{2} \mathrm{NW}$ was identified to be of a single crystalline type(not shown). The $\mathrm{SnO}_{2}$ NWs were confirmed to have a rutile structure by Xray diffraction measurements(Fig. 2b). The TEM images of Pd- and Ag-loaded $\mathrm{SnO}_{2} \mathrm{NWs}$ are shown in Fig. 3. The nanoparticles(size: $\sim 15 \mathrm{~nm}$ ) were uniformly distributed on the $\mathrm{SnO}_{2}$ NWs, seen in Fig. 3a and Fig. 3c, were identified as $\mathrm{Pd}$ and $\mathrm{Ag}$, respectively, by energy dispersive spectroscopy analyses(Figs. $3 \mathrm{~b}$ and $3 \mathrm{~d}$ ). The $\mathrm{Cu}$ peaks in the EDS spectra of Figs. $3 \mathrm{~b}$ and $3 \mathrm{~d}$ emanate from the $\mathrm{Cu}$ grid used for the TEM analysis. The results show that slurry dropping provides a simple, effective route to load $\mathrm{Pd}$ or Ag nanoparticles on oxide NWs in a uniform manner.
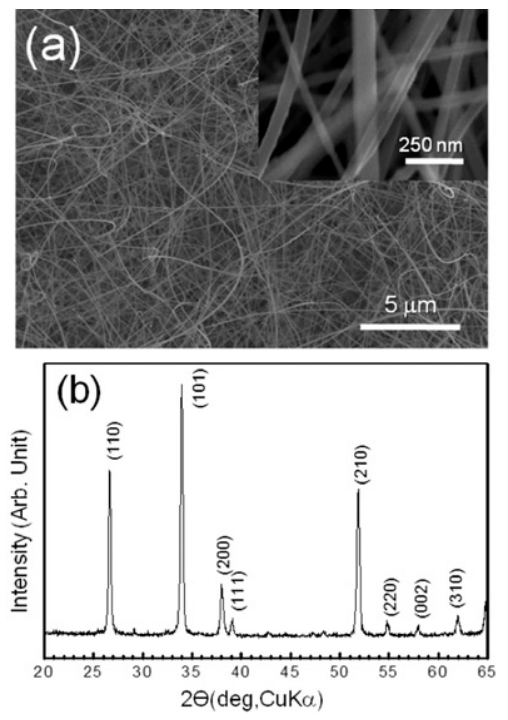

Fig. 2. (a) SEM images and (b) X-ray diffraction pattern of pristine $\mathrm{SnO}_{2}$ nanowires. 

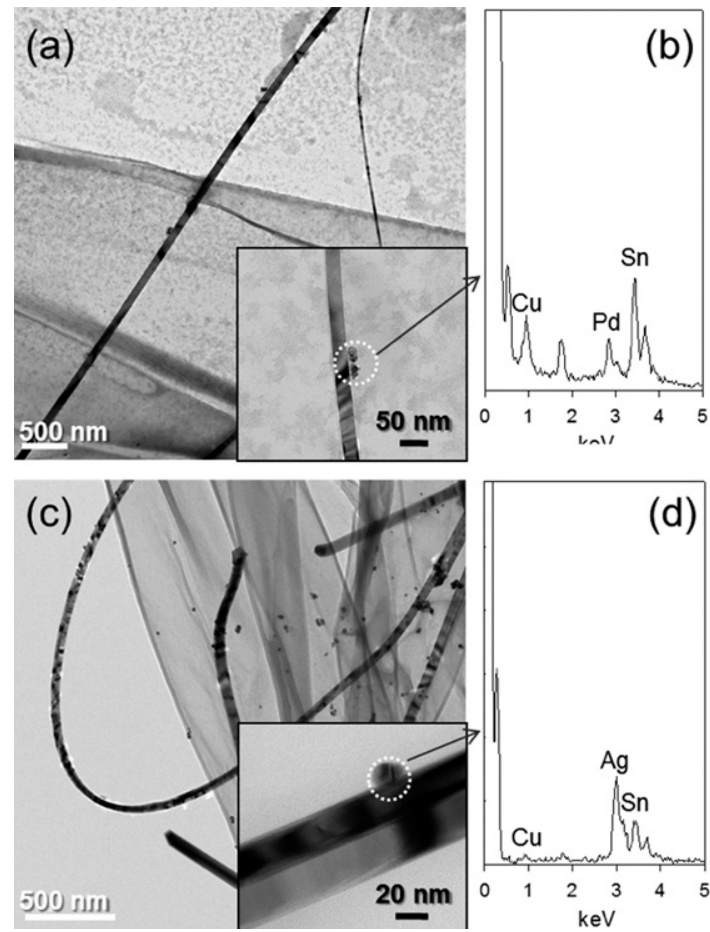

Fig. 3. TEM images and EDS results for (a,b) Pd-loaded $\mathrm{SnO}_{2}$ nanowires and (c,d) Ag-loaded $\mathrm{SnO}_{2}$ nanowires.

\subsection{Gas sensing characteristics}

Gas responses to $100 \mathrm{ppm} \mathrm{CO}, \mathrm{H}_{2}, \mathrm{C}_{3} \mathrm{H}_{8}, \mathrm{NH}_{3}$, and $\mathrm{C}_{2} \mathrm{H}_{5} \mathrm{OH}$ of pristine, Pd-loaded and $\mathrm{Ag}$-loaded $\mathrm{SnO}_{2} \mathrm{NWs}$ were measured at $380^{\circ} \mathrm{C}$ (Fig. 4). In the pristine $\mathrm{SnO}_{2} \mathrm{NW}$ sensor, the response to $100 \mathrm{ppm} \mathrm{C}_{2} \mathrm{H}_{5} \mathrm{OH}\left(R_{d} / R_{g}=207.6\right)$ is significantly higher than the responses to other gases $\left(R_{d} / R_{g}\right.$ $=4.1-11.5$ ), indicating the selective detection of $\mathrm{C}_{2} \mathrm{H}_{5} \mathrm{OH}$. After the loading of Pd, both the response to $100 \mathrm{ppm} \mathrm{CO}$ and $\mathrm{H}_{2}$ increased $\sim 2.7$ times while the enhancement of the responses to $\mathrm{C}_{3} \mathrm{H}_{8}$ and $\mathrm{NH}_{3}$ is relatively small. On the

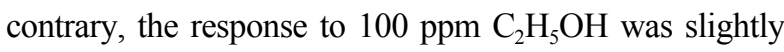
decreased by the Pd loading.

In general, the loading of noble metal catalysts are known to improve gas sensing characteristics of oxide semiconductors[8]. However, the role of Pd in terms of gas response seen in various literatures has not always been consistent[12-16]. For example, Pd loading either increased or decreased gas responses according to the loading concentration[12-14] and loading method[12, 15] of the Pd catalysts as well as the optimum sensing temperature[14, 16]. In addition, the gas selectivity was also changed by $\mathrm{Pd}$ loading. Although the response to $\mathrm{C}_{2} \mathrm{H}_{5} \mathrm{OH}$ sensor is still markedly higher than to other gases after Pd loading, the selectivity to $\mathrm{C}_{2} \mathrm{H}_{5} \mathrm{OH}$ slightly deteriorated.

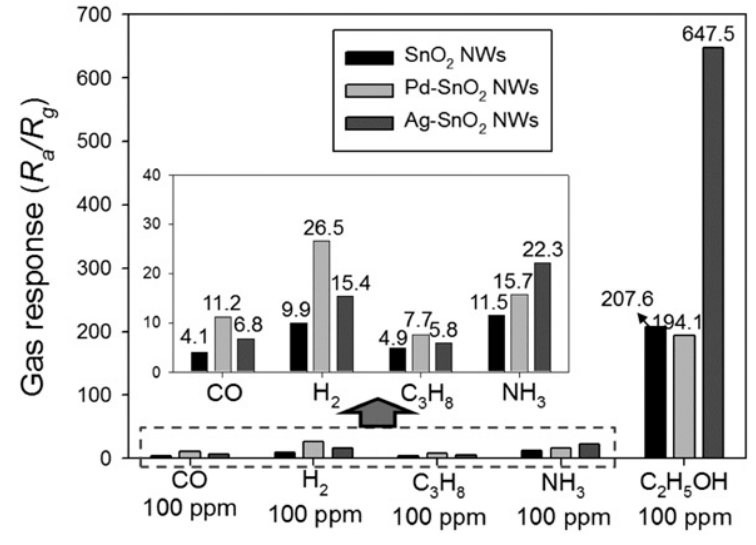

Fig. 4. Gas responses to $100 \mathrm{ppm} \mathrm{CO}, \mathrm{H}_{2}, \mathrm{C}_{3} \mathrm{H}_{8}, \mathrm{NH}_{3}$ and $\mathrm{C}_{2} \mathrm{H}_{5} \mathrm{OH}$ of pristine $\mathrm{SnO}_{2}$ nanowires, Pd-loaded $\mathrm{SnO}_{2}$ nanowires and $\mathrm{Ag}$-loaded $\mathrm{SnO}_{2}$ nanowires at $380^{\circ} \mathrm{C}$.

The loading of Ag leads to different sensing behaviors. The enhancement of response to $\mathrm{C}_{2} \mathrm{H}_{5} \mathrm{OH}$ was 3.1-fold, while the responses to $\mathrm{CO}, \mathrm{H}_{2}, \mathrm{C}_{3} \mathrm{H}_{8}$, and $\mathrm{NH}_{3}$ were increased only 1.2 times $\sim 1.7$ times. That is, Ag loading enhances the selectivity to $\mathrm{C}_{2} \mathrm{H}_{5} \mathrm{OH}$ to a great degree. This means that highly sensitive and selective $\mathrm{C}_{2} \mathrm{H}_{5} \mathrm{OH}$ sensors can be made using Ag-loaded $\mathrm{SnO}_{2} \mathrm{NW}$ networks.

The sensing transients of the $\mathrm{Ag}-\mathrm{SnO}_{2} \mathrm{NW}$ network sensor to $10 \mathrm{ppm} \sim 100 \mathrm{ppm} \mathrm{C}_{2} \mathrm{H}_{5} \mathrm{OH}$ are shown in Fig. 5(a). The sensor resistance decreased upon exposure to $\mathrm{C}_{2} \mathrm{H}_{5} \mathrm{OH}$ and recovered in a stable manner upon exposure to air. The responses to $\mathrm{C}_{2} \mathrm{H}_{5} \mathrm{OH}$ of pristine $\mathrm{SnO}_{2}$ and $\mathrm{Pd}-$ $\mathrm{SnO}_{2} \mathrm{NW}$ sensors at $380^{\circ} \mathrm{C}$ are compared in Fig. 5(b). The responses to $10 \mathrm{ppm} \sim 100 \mathrm{ppm}_{2} \mathrm{H}_{5} \mathrm{OH}$ ranged from 42.4 to 210 in the $\mathrm{SnO}_{2}$ NW sensor, this is significantly enhanced to 188 to 634 by loading Ag onto the sensor. The $\mathrm{C}_{2} \mathrm{H}_{5} \mathrm{OH}$ response of the $\mathrm{Ag}-\mathrm{SnO}_{2} \mathrm{NW}$ sensors in the present study is higher than the Ag-loaded $\mathrm{TiO}_{2}$ nanobelts[17], the $\mathrm{Ag}$-loaded $\mathrm{ZnO}$ nanorods[18], and the Ag-loaded $\mathrm{TiO}_{2}$ spherical heterostructures[19]. In particular, considering the very high response to $10 \mathrm{ppm}$ $\mathrm{C}_{2} \mathrm{H}_{5} \mathrm{OH}\left(R_{a} / R_{g}=188\right)$, detection of sub-ppm levels of $\mathrm{C}_{2} \mathrm{H}_{5} \mathrm{OH}$ seems to be possible using Ag-loaded $\mathrm{SnO}_{2} \mathrm{NW}$ networks.

'Electronic sensitization' and 'chemical sensitization' are the two main sensitization mechanisms of noble metal catalysts in the gas sensing reaction[20]. The former mechanism is explained by the extension of an electron depletion layer beneath the $\mathrm{Ag}$ catalyst nanoparticles and a consequent enhancement of gas response. The latter is explained by a 'spill-over effect' to promote the dissociation of reducing gases. At this moment, the 
dominant sensitization mechanism is not clear and should be studied further. The gas responses and selectivities as a function of the morphology, size and distribution of $\mathrm{Ag}$ catalysts will be an effective way to elucidate the sensing mechanism. Finally, the results in Fig. 4 show the gas response and selectivity can be tuned by the proper use of noble metal catalysts and sensor data with various sensing materials will provide valuable sensing libraries for pattern recognition of multi-component chemicals.


Fig. 5. (a) Gas sensing transients and (b) gas responses to $100 \mathrm{ppm}$ $\sim 10$ ppm $\mathrm{C}_{2} \mathrm{H}_{5} \mathrm{OH}$ of the Ag-loaded $\mathrm{SnO}_{2}$ nanowires at $380^{\circ} \mathrm{C}$.

\section{CONCLUSIONS}

The gas sensing characteristics of $\mathrm{SnO}_{2}$ nanowire network sensors were modified or enhanced by $\mathrm{Pd}$ and $\mathrm{Ag}$ nanoparticles. Pristine $\mathrm{SnO}_{2}$ nanowire networks showed the selective detection of $\mathrm{C}_{2} \mathrm{H}_{5} \mathrm{OH}$ with low crossresponses to $\mathrm{CO}, \mathrm{H}_{2}, \mathrm{C}_{3} \mathrm{H}_{8}$ and $\mathrm{NH}_{3}$. The loading of $\mathrm{Pd}$ did not vary the response to $\mathrm{C}_{2} \mathrm{H}_{5} \mathrm{OH}$ but significantly increased responses to $\mathrm{CO}$ and $\mathrm{H}_{2}$, which in turn deteriorated the sensor's selectivity to $\mathrm{C}_{2} \mathrm{H}_{5} \mathrm{OH}$. The loading of Ag induced a 3.1-fold increase in the $\mathrm{C}_{2} \mathrm{H}_{5} \mathrm{OH}$ response, which leaded to highly selective and sensitive detection of $\mathrm{C}_{2} \mathrm{H}_{5} \mathrm{OH}$.

\section{REFERENCES}

[1] A. Kolmakov and M. Moskovits, "Chemical sensing and catalysis by one-dimensional metal-oxide nanostructures", Annu. Rev. Mater. Res. vol. 34, pp. 151-180, 2004.

[2] I.-S. Hwang and J.-H. Lee, "Gas sensors using oxide nanowire networks: An overview", J. Nanoeng. Nanomanf., vol. 1, pp. 4-17, 2011.

[3] Z. Fan, D. Wang, P. C. Chang, W. Y. Tseng, and J. G. $\mathrm{Lu}$, "ZnO NW field-effect transistor and oxygen sensing property", Appl. Phys. Lett., vol. 85, pp. 59235925, 2004.

[4] X. Duan, Y. Huang, Y. Cui, J. Wang, and C. M. Lieber, "Indium phosphide nanowires as building blocks for nanoscale electronic and optoelectronic devices", Nature, vol. 409, pp. 66-69, 2001.

[5] I.-S. Hwang, Y.-S. Kim, S.-J. Kim, B-K. Ju, and J.-H. Lee, "A facile fabrication of semiconductor nanowires gas sensor using PDMS patterning and solution deposition", Sens. Actuators B, vol. 136, pp. 224-229, 2009.

[6] Y.-J. Choi, I.-S. Hwang, J.-G. Park, K.J. Choi, J.-H. Park, and J.-H. Lee, "Novel fabrication of $\mathrm{SnO}_{2}$ nanowire gas sensor with a high sensitivity", Nanotechnology, vol. 19, p. 095507, 2008.

[7] I.-S. Hwang, E.-B. Lee, S-J. Kim, J.-K. Choi, J.-H. Cha, H.-J. Lee, B.-K. Ju, and J.-H. Lee, "Gas sensing properties of $\mathrm{SnO}_{2}$ nanowires on micro heater", Sens. Actuators B, vol. 154, pp. 295-300, 2009.

[8] A. Kolmakov, D. O. Klenov, Y. Lilach, S. Stemmer, and M. Moskovits, "Enhanced gas sensing by individual $\mathrm{SnO}_{2}$ nanowires and nanobelts functionalized with Pd catalyst particles", Nano Lett., vol. 5, pp. 667673, 2005.

[9] Y. Zhang, J. Xu, P. Xu, Y. Zhu, X. Chen, and W. Yu, "Decoration of $\mathrm{ZnO}$ nanowires with $\mathrm{Pt}$ nanoparticles and their improved gas sensing and photocatalytic performances", Nanotechnology, vol. 21, p. 285501, 2010.

[10] I.-S. Hwang, J.-K Choi, S.-J. Kim, K.-Y. Dong, J.-H. Kwon, B.-K. Ju, and J.-H. Lee, "Enhanced $\mathrm{H}_{2} \mathrm{~S}$ sensing characteristics of $\mathrm{SnO}_{2}$ nanowires functionalized with CuO”, Sens. Actuators B, vol. 142, pp. 105-110, 2009. 
[11] C.J. Murphy, T.K. Sau, A.M. Gole, C. J. Orendorff, J. Gao, L. Gou, S. E. Hunyadi, and T. Li, "Anisotropic metal nanoparticles: synthesis, assembly and optical applications", J. Phys. Chem. B, vol. 109, pp. 13857$13870,2005$.

[12] S. Matsushima, T. Maekawa, J. Tamaki, N. Miura, and N. Yamazoe, "New methods for supporting palladium on a tin oxide gas sensor", Sens. Actuators $B$, vol. 9, pp. 71-78, 1992.

[13] M. Yuasa, T. Masaki, T. Kida, K. Shimanoe, and N. Yamazoe, "Nano-sized $\mathrm{PdO}$ loaded $\mathrm{SnO}_{2}$ nanoparticles by reverse micelle method for highly sensitive $\mathrm{CO}$ gas sensor", Sens. Actuators B, vol. 136, pp. 99-104, 2009.

[14] J.-K. Choi, I.-S. Hwang, S.-J. Kim, J.-S. Park, S.-S. Park, U. Jeong, Y.C. Kang, and J.-H. Lee, "Design of selective gas sensors using electrospun Pd-doped $\mathrm{SnO}_{2}$ hollow nanofibers", Sens. Actuators B, vol. 150, pp. 191-199, 2010.

[15] C. -B. Lim and S. Oh, "Microstructure evolution and gas sensitivities of $\mathrm{Pd}$-doped $\mathrm{SnO}_{2}$-based sensor prepared by three different catalyst-addition process", Sens. Actuators B, vol. 30, pp. 223-231, 1996.
[16] L.Liu, T. Zhang, S. Li, L. Wang, and T. Tian, "Preparation, characterization, and gas-sensing properties of Pd-doped $\mathrm{In}_{2} \mathrm{O}_{3}$ nanofibers", Mater. Lett., vol. 63, pp. 1975-1977, 2009.

[17] P. Hu, G. Du, W. Zhou, J. Cui, J. Lin, H. Liu, D. Liu, J. Wang, and S. Chen, "Enhancement of ethanol vapor sensing of $\mathrm{TiO}_{2}$ nanobelts by surface engineering", ACS Appl. Mater. Interfaces, vol. 2, pp. 3263-3269, 2010.

[18] Q. Xiang, G. Meng, Y. Zhanga, J. Xu, P. Xu, Q. Pan, and $\mathrm{W}$. Yu, "Ag nanoparticle embedded-ZnO nanorods synthesized via a photochemical method and its gassensing properties", Sens. Actuators B, vol. 143, pp. 635-640, 2010.

[19] X. Cheng, Y. Xu, S. Gao, H. Zhao, and L. Huo, “Agnanoparticles modified $\mathrm{TiO}_{2}$ sphereical heterostuctures with enhanced gas-sensing performances", Sens. Actuators B, vol. 155, pp. 716-721, 2011.

[20] N. Yamazoe, "New approaches for improving semiconductor gas sensors", Sens. Actuators B, vol. 5, pp. 7-19, 1991.

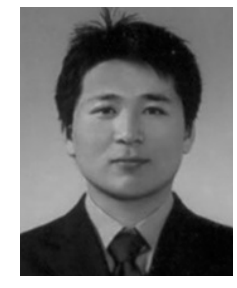

In-Sung Hwang received his B.S. from Kumoh National Institute of Technology (KIT), Korea, in 2004. He received his M.S. and Ph.D. degrees from Korea University in 2006 and 2011, respectively. In 2009, he was a visiting researcher for Inorganic Chemistry and Electrochemistry at RWTH Aachen University(Germany) for 3 months. He was post-doctoral researcher at Korea University in 2011. Now, he is research associate at University of Central Florida, USA. His research interests are synthesis of semiconductor nanostructures and fabrication of electronic devices such as chemical sensors, optical sensors and Li-ion secondary batteries.

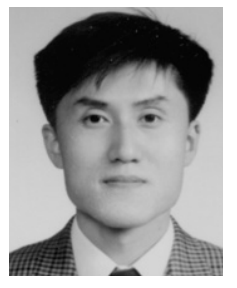

Jong-Heun Lee joined the Department of Materials Science and Engineering at Korea University as an Associate Professor in 2003, where he is currently a Professor. He received his B.S., M.S. and Ph.D. degrees from Seoul National University in 1987, 1989 and 1993, respectively. Between 1993 and 1999, he developed automotive air-fuel-ratio sensors at the Samsung Advanced Institute of Technology. He was a Science and Technology Agency of Japan(STA) fellow at the National Institute for Research in Inorganic Materials(currently NIMS, Japan) from 1999 to 2000 and a Research Professor at Seoul National University from 2000 to 2003 . His current research interests include chemical sensors, functional nanostructures and solid oxide electrolytes. 